\title{
LA ESTRATEGIA ANTIROMANA DE BERNARDO TANUCCI ANTE LOS ACONTECIMIENTOS DE 1768
}

\section{Gaetano CERCHIELLO}

Universidad de Alicante

«Il bastone alto, la bocca chiusa son li strumenti colli quali si deve mansuefare la tigre romana»!

\section{Resumen}

La lucha entre la Santa Sede y las Cortes Borbónicas que caracterizó el pontificado de Clemente XIII, llegó a su culminación en el año 1768 tras la condena papal del Duque de Parma, Fernando de Borbón, y sus ministros. La respuesta de Francia y España, que se materializó sustancialmente con las represalias militares de Aviñón, Benevento y Pontecorvo, fue asumida con mucha resignación por el Secretario de Estado de Nápoles, Bernardo Tanucci. El análisis de su correspondencia confidencial con el Secretario de Estado de España, Jerónimo Grimaldi, y con el Rey Carlos III, nos da una imagen bastante clara del planteamiento del Ministro sobre los acontecimientos de ese año, poniendo de relieve el aislamiento y la derrota de su línea política.

\begin{abstract}
The fight among the Papal Seat and the Bourbon Courts that characterised the reign of Clement XIII, arrived at its culmination in the year 1768 after the Pope condemned the Duke of Parma, Fernando of Bourbon, and its ministers. The response of France and Spain, which materialised substantially with the military reprisals of Avignon, Benevento and Pontecorvo, was accepted with a lot of resignation by the State Secretary of Naples, Bernardo Tanucci. The analysis of his confidential correspondence with the State Secretary of Spain, Jerónimo Grimaldi, and with the King Charles III, gives us a clear enough image of the Minister position as regards the events of that year, showing the isolation and the defeat of his political line.
\end{abstract}

* Queremos agradecer a Marta Díez Sánchez tanto la corrección de estilo de este trabajo, como su infinita paciencia y comprensión a la hora de efectuarla.

1. Carta de Bernardo Tanucci a Ferdinando Galiani, 29 de abril de 1768, citada en Rosa MINCUZZI, Bernardo Tanucci Ministro di Ferdinando di Borbone, (1759-1776), Dedalo Libri, Bari, 1967, página 76. 


\section{EL MONITORIO DE PARMA}

El 30 de enero de 1768, el Papa Clemente XIII expidió el Edicto Alias ad Apostolatus, más conocido como el «Monitorio de Parma», con el cual, en virtud de los derechos territoriales de la Santa Sede sobre el Ducado de Parma y de la bula In Coena Domini, anulaba los últimos decretos en materia eclesiástica del Estado parmesano y excomulgaba al Duque Fernando y a sus ministros. De esta manera, la Santa Sede quiso condenar toda la política regalista dirigida por el Secretario de Estado, Guillermo Du Tillot, y hecho más grave, declaraba ilegítima la autoridad con la que habían sido emanados, esto es, impugnaba los derechos de soberanía del Duque Fernando, sobrino de Carlos III y de Luis $\mathrm{XV}^{2}$. El Breve papal, que cogió por sorpresa a los Borbones y a sus ministros, iba a empeorar las relaciones ya tensas entre Roma y las cortes borbónicas, tras la expulsión de los jesuitas de Francia, España, y por último, de Nápoles. Además, en la noche del día 7 al 8 de febrero, se ejecutó, «con indecible tranquilidad», el desalojo de todos los Regulares de la Compañía de Jesús de los dominios del Duque Fernando, según un plan ya predispuesto y preparado por Du Tillot a mediados del año anterior ${ }^{3}$. Es evidente que la expulsión de alrededor de 170 religiosos, llevada a cabo 8 días después de la publicación del Breve, representaba una replica al «atentado» de la Curia romana, empeorando aún más las relaciones entre la Casa de Borbón y la Santa Sede 4 .

El asunto de Parma puso de manifiesto la disparidad de opiniones entre el Gobierno de Nápoles, por una parte, y los de Francia y España por otra, a propósito de la línea política que había que adoptar sobre este asunto, y más en general, sobre la manera de tratar con Roma. No cabe duda de que tanto la Corte de París como la de Madrid, unidas por el Pacto de Familia desde agosto de 1761, no esperaban una decisión tan atrevida y directa de Roma, y desde el principio vieron en ella la mano de los jesuitas y del Secretario de Estado de la Santa Sede, el Cardenal Torrigiani ${ }^{5}$ :

2. Objeto de la condena papal fueron los edictos que a partir del año 1764 iban a limitar algunos privilegios eclesiásticos. Entre ellos destacan: el de 25 de octubre de 1764 sobre los bienes de manomorta; la orden de 13 de enero de 1765 sobre la perequazione dei carichi pubblici, y sobre todo la ley del 16 de enero 1768 que prohibía a los súbditos la posibilidad de apelar a los tribunales romanos, como a los demás tribunales extranjeros, y además establecía el exequatur para las bulas y los breves papales. Sobre el Monitorio de Parma y la complicada cuestión de los derechos a la soberanía del Ducado de Parma, véase la imprescindible obra de Manuel DANVILA, Historia General de España. El Reinado de Carlos III, El Progreso, Madrid, 1891, tomo III, páginas 171-230.

3. Archivo General de Simancas (en adelante A.G.S.), Estado, legajo (en adelante leg.) 5055, carta de $\mathrm{Du}$ Tillot a Grimaldi, Parma 14 de junio de 1767. Sobre los preparativos de la expulsión, véase también una carta del Conde de Aranda al Secretario de Gracia y Justicia español, Manuel Roda, de 29 de mayo de 1767, en la que se informa de la opinión del Consejo Real de España sobre los métodos propuestos por Du Tillot, en A.G.S., Estado, leg. 5055

4. A.G.S., Estado, leg. 5055, carta de Du Tillot a Grimaldi, 10 de febrero de 1768. El decreto de expulsión fue firmado el día 3 de febrero. Una copia del decreto en Archivo Ministerio Asuntos Exteriores (en adelante A.M.AA.EE,) Santa Sede, Leg. 427.

5. Nombrado por Benedicto XIV Secretario de la Consulta en 1743 y Cardenal el 26 de noviembre de 1753, Luigi Maria Torrigiani fue designado por Clemente XIII para dirigir la Secretaría de Estado en 1758. 
«Ya estará VE. perfectamente instruido -informa Grimaldi en una carta a Tanuccidel paso escandaloso á que Torriggiani y sus seqüaces se han precipitado contra el Señor Infante Duque de Parma (...). Nos llegó el Jueves [18 de febrero] esta noticia que sorprendió á todos, y causó al Rey la mayor extrañeza; y habiendo reflexionado S.M. el fin á que se dirixe un atentado tan horrendo, determinó inmediatamente oponerse á las ideas de Roma, no solo para libertar al Infante su sobrino de la opresión en que se intenta ponerle, sino también por que su causa comprende á todos los soberanos católicos»".

Con el Monitorio de Parma, pues, se había querido perjudicar a toda la Casa de Borbón, y por ello se exigía proceder de forma conjunta para «solicitar el reparo a los insultos declarados en dicho Breve, instando sobre su solemne revocación» ${ }^{7}$. $\mathrm{Pa}-$ ra los ministros franceses y españoles era imprescindible la retractación del Monitorio, meditando «represalias» si Clemente XIII rechazaba la instancia.

El Marqués Bernardo Tanucci coincidía con la opinión de que el Monitorio, «impasto di massime strane non cristiane orgogliose [y] sediziose $»^{8}$, representaba un ataque a toda la familia de los Borbones y una «vendetta» por la expulsión de los jesuitas. Afirmaba que desde l' «Interdetto di Venezia» ${ }^{9}$, Roma no había «dato un passo tanto spropositato quanto è questo contro Parma» ${ }^{10}$. Según el Ministro, que en los días siguientes a la publicación del Breve no escondió su cólera, la única punición adecuada a la «ultima ferocia» del Papa debía ser la de quitarle la temporalidad, si bien era consciente de la impracticable de su propuesta. En una carta a Grimaldi, con fecha 9 de febrero, el Ministro napolitano exclamaba:

«Ah, io non avrei voluto toccar questo tasto dell'editto de Roma, abrogatorio di tutti gli editti di Parma, che riguardava li beni e la giurisdizione, non la fede, non il rito, non li Sacramenti (...). Il rimedio contro li Vescovi abusanti, é il privarli della temporalitá; abuso dunque del Papa dovrebbe farsi col privarlo dello Stato temporale»."

6. A.G.S., Estado, leg. 6101, Grimaldi a Tanucci, 23 de febrero de 1768. Idéntica fue la interpretación del Primer Ministro francés, el Duque de Choiseul, mientras que, según informa Grimaldi, el Parlamento de París calificó al Monitorio de Parma «con la misma indignación» que el Consejo Real espanol, en A.G.S., Estado, leg. 6101, Grimaldi a Tanucci, El Pardo, 22 de marzo de 1768.

7. A.M.AA.EE, Santa Sede Leg. 427, carta del Embajador en España, Tomás Azpuru, a Guillermo Du Tillot, Roma, 31 de marzo de 1768 .

8. A.G.S., Estado, leg. 6101, Tanucci a Grimaldi, 29 de noviembre de 1768.

9. Tanucci hace referencia en este caso a una bula promulgada el 17 de abril de 1606 por Pablo V conocida como l' 'Interdicto contra Venecia», en virtud de la cual, el Papa Camillo Borghese (Roma 1552Roma 1621) amenazaba con excomulgar al Senado de la República adriática y «d'interdit tout le territoire de Venise», si no se procedía a la abrogación de dos disposiciones perjudiciales para algunos privilegios eclesiásticos, y si el Senado no decretaba la liberación de dos clérigos rebeldes; en Dictionnairre de Théologie Catholique, París, Tomo XII, 1933, página 24-31.

10. A.G.S., Estado, leg. 6101, Tanucci a Grimaldi, 1 de noviembre de 1768 , y también carta de Tanucci a Grimaldi de 15 de marzo de 1768.

11. A.G.S., Estado, leg. 6101, Tanucci a Grimaldi, 9 de febrero de 1768. En una carta al Secretario de la embajada de Nápoles en Francia, Ferdinando Galiani, Tanucci añadía: «Parma inveita, scomunicata, abrogata, detronata con un editto da lupi della Sannita dovrebbe attenersi al silenzio e alla natura, quando li Borboni tutti non si uniscono a detronar il papa, dividendo lo stato tra Venezia, Granduca, 
En realidad, desde el inicio de la crisis, Tanucci intentó convencer a Carlos III de que el Monitorio, «editto imprudente, temerario, insolente e manifestatamente dettato dai Gesuiti ${ }^{12}$, era en realidad una maniobra de éstos para forzar a los Borbones a tener que tratar con Roma; «colla fiducia antica -añadía el Ministro- di che ove Roma parla, guadagna» ${ }^{13}$. Por este motivo, aconsejaba al Rey «di non attaccar discorso» con Roma, porque, en caso contrario, se caía en la trampa de los jesuitas «regolatori delle coscienze dei Papi» y del Cardenal Torrigiani:

«L'aforismo dunque, che io vedo utile ai Sovrani Cattolici, é il mettere in sicuro la coscienza colla vera dottrina, e ragione Cristiana, e di Stato, e col consiglio, e parere di uomini gravi, dotti, religiosi, prudenti, e messa la coscienza in sicuro, operar francamente, senza parlar con Roma; parlando si fará il negozio di Torrigiani, e dei Gesuiti, li quali su questo sperano" ${ }^{14}$.

La línea política que el Ministro indicaba como la única que habría producido resultados positivos en esta disputa con «la cittá dei preti», era simplemente no tratar con ésta y adoptar un firme «silenzio» ante su actitud:

«Non è questo Pontificado per cose grandi ne per opere che esigono mente luminosa, e cuore generoso (...), dunque sará miglior partito quello del silenzio, e di continuare lo stato presente ${ }^{15}$.

Como demuestra la correspondencia semanal mantenida con Carlos III y con Grimaldi, esta sugerencia se repetirá puntualmente ${ }^{16}$. Por lo tanto, el Ministro estimaba conveniente obviar las provocaciones de Roma, y se mostraba contrario a iniciativas dirigidas a solicitar la revocación del Breve, puesto que con este tipo de conducta se habría dado la impresión de necesitarla, otorgando así mayor poder de negociación a la Curia romana. Además, con referencia a la excomunión conminada por la Curia romana al Duque Fernando y a sus ministros, se trataba de un procedimiento anacrónico, que en su opinión, no habría producido ningún efecto:

Modena, Sicilie. Il delitto di Roma non si puó espiare con altro che col silenzio e disprezzo o con toglierle la sovranità temporale, senza la quale cesserebbero gli abusi anche nello spirituale. Non intendo il pensare dei gabinetti cattolici. Se un vescovo è insolente, per poco che lo sia, subito si va a toglierli le temporalità. I papa è l'ente più insidioso, più micidiale a tutte le sovranitá, e non si pensa a privarlo di quelle temporalità, per la quale ha abbandonato la legge di Gesù Cristo, la dottrina sua e quella degli Apostoli, che è la sola vera», citado en Rosa MINCUZZI, Bernardo Tanucci Ministro di Ferdinando di Borbone..., pág. 74-75. Sobre este tema, puede consultarse también Pia ONNIS, «Bernardo Tanucci nel moto anticurialista del settecento», en Filippo Buonarroti e altri studi, Roma, $1971^{2}$, pág. 373.

12. A.G.S., Estado, leg. 6101, Tanucci a Grimaldi, 9 de febrero de 1768.

13. A.G.S., Estado, leg. 6101, Tanucci a Carlos III, 9 de febrero de 1768. Sobre este tema remitimos al interesante ensayo de Maria Claudia FERRARI, «ll problema della soppressione della Compagnia di Gesù nel carteggio di Bernardo Tanucci», en Storia e Politica, IV, 1980, n 19, pág. 664.

14. A.G.S., Estado, leg. 6101, Tanucci a Carlos III, 15 de marzo de 1768.

15. A.G.S., Estado, leg. 6101, Tanucci a Grimaldi, 25 de octubre de 1768.

16. A.G.S., Estado, leg. 6101. Véase entre otras las cartas de Tanucci a Carlos III, de I de marzo, 15 de marzo, y 17 de mayo de 1768. En la carta a Grimaldi de 9 de febrero, Tanucci ya explicaba que «forse é meglio tacere e fare il fatto suo». 
«Roma stessa sà il torto che ha nell'affare di Parma; son per prova, che li popoli Italiani conoscono le arti mondane di essa, né si commuovono per li stati interdetti e scomuniche, lasciate per lo piú ingiustamente perché per cose temporali» ${ }^{17}$.

Sin embargo, a pesar del dictamen del Secretario de Estado y de la Real Cámara de Nápoles ${ }^{18}$, Francia y España decidieron «caminar unidas con vigoroso empeño al desagravio, y satisfacción de la ofensa» ${ }^{19}$, esto es, pedir oficialmente al Papa la retractación del formabrevis, mandando al mismo tiempo que Nápoles se adhiriera a la decisión ya tomada. En una carta enviada por Grimaldi a Tanucci a finales de marzo, se informaba que «en París se han conformado absolutamente con el Plan», haciendo así entender que la iniciativa había salido de la Corte de Madrid ${ }^{20}$. El Embajador de Francia en Nápoles, el Vizconde de Choiseul, confirmaba el acuerdo entre las dos Cortes, y a lo largo de una conferencia con Tanucci, le comunicaba que el Rey de Francia se había conformado «totalmente» con el «metodo da tenersi in Roma per le cose di Parma ${ }^{21}$. Dicho plan preveía que los tres embajadores en Roma, Aubeterre ${ }^{22}$, Azpuru y Orsini ${ }^{23}$, hicieran su primer paso conjuntamente en nombre del Duque de Parma, entregando al Pontífice, «senza passare pel Segretario di Stato, o per altro Canale» una «Memoria» del Duque, junto a un «Manifiesto» redactado en Parma y ya difundido en Roma, para que pudiera «contribuir a animar mayormente el contes-

17. A.G.S., Estado, leg. 6101, Tanucci a Carlos III, 15 de marzo de 1768.

18. «Se questo mio amabile Padrone -escribía Tanucci a Carlos III- mi comandasse il mio parere, sarei sempre dello stesso. Roma vuol parlare, e vuole entrare colla solita sediziosa maniera», en A.G.S., Estado, leg. 6101, carta de 8 de marzo.

19. A.M.AA.EE, Santa Sede Leg. 427, carta de Tomás Azpuru a Guillermo Du Tillot, Roma, 31 de marzo de 1768 .

20. A.G.S., Estado, leg. 6101, carta de Grimaldi a Tanucci de 29 de marzo. Que la iniciativa fuera española, lo demuestra una carta de Du Tillot a Azpuru de 24 de marzo, en la que el Secretario de Estado de Parma afirmaba: «Parece que todo lo que se havía resuelto en Madrid, y que se dejaba después a la decisión del Rey Cristianísimo ha sido en todo admitido por S.M. Cristianísima», en A.M.A.A.EE, Santa Sede Leg. 427.

21. A.G.S., Estado, leg. 6101, carta de Tanucci a Carlos III, 29 de marzo de 1768. Tan reiteradas eran las críticas dirigidas al joven Embajador de Francia, que nos resulta prácticamente imposible citar todas las veces que Tanucci se queja de su conducta. Como resumen de todas ellas, véase la carta a Carlos IIl de 16 de mayo de aquel año, en la que el Ministro, utilizando una típica expresión napolitana, escribe que éste era «veramente una poca cosa», en A.G.S., Estado, leg. 6101.

22. Joseph Henry Bouchard d'Esparbés de Lussan (1714-1788), Marqués d'Aubeterre, fue Embajador francés en Viena, y luego en Madrid desde abril de 1757 hasta el 15 de enero de 1760, cuando, tras una petición de Carlos III, fue sustituido por el Marqués de Ossun. Cinco años más tarde fue enviado a Roma para desempeñar el difícil cargo de Embajador, que mantuvo hasta el Cónclave de 1769.

23. Nacido en Nápoles en junio de 1719, Domenico Orsini era hijo del duque de Gravina, Filippo Bernualdo y de Giacinta Marescotti Ruspoli, y sobrino de Benedicto XIII (Pier Francesco Orsini). En 1734, Carlos de Borbón le nombra Gentilhombre de Cámara y en 1739 Cavaliere di San Gennaro. Se casó con Ana Faminia que muere después de haberle dado un hijo, Filippo Bernualdo a quien cedería el título de duque. El 9 de septiembre de 1743 es creado Cardenal por Benedicto XIV, que a su vez había obtenido el capelo cardinalicio por el Papa Orsini. En 1759 fue designado Embajador de Nápoles ante la Corte pontificia. Murió en Roma en enero de 1789. 
to de aquella [Corte], y disponer la resolución coherente a la instancia» ${ }^{24}$. Según Tanucci, que desde el principio se mostró escéptico sobre el buen resultado de la iniciativa, el Manifiesto de Parma había sido «forse troppo presto, e troppo copiosamente diffuso in Roma», dando a los «palatini» tiempo para «concertar la risposta, ed sconcertar in qualche maniera il Piano» ${ }^{25}$. Los temores del Ministro sobre el éxito del paso dado se demostraron fundados. A tenor de las órdenes recibidas por las respectivas Cortes, el día 28 de marzo los tres embajadores pidieron audiencia en nombre del Infante Duque de Parma, y «con la prevención» de que debían «ir unidos a ella». Sin embargo, dos días después, Clemente XIII resolvió, que

«no podía admitir unidos a los ministros de las tres Cortes, aunque fuese único el objeto de su audiencia, impidiéndola el darla en esta forma la diversidad de sus caracteres, y la del ceremonial que debe observar cada uno ${ }^{26}$.

Asimismo, comunicaba «por medios del Cardenal Nepote» ${ }^{27}$, que los habría recibido y dado «audiencia a todos tres separadamente», aunque sólo una vez transcurrida Pascua, es decir, por lo menos a partir del día 4 de abril. La negativa dada por Clemente XIII a la audiencia en común, por motivos de «ceremonial y etiqueta», representaba, según Azpuru, el «sólito arvitrio» de la Corte de Roma «para ganar tiempo» y «para huir de la dificultad en los negocios, en que no pueda sostener sus ideas infundadas» ${ }^{28}$, pero, sobre todo, era una señal de la resistencia de Roma a aceptar las pretensiones de los Borbones. Así, tras una reunión en la residencia romana del Embajador de Nápoles, se decidió que fuera a la audiencia sólo Azpuru, «en nombre de todos», aunque Orsini había señalado en un primer momento que «haviéndose pedido la audiencia a nombre de los tres, no parecía consiguiente el ir uno sólo» ${ }^{29}$. A

24. A.M.AA.EE, Santa Sede, Leg. 427, carta de Tomás Azpuru a Guillermo Du Tillot, Roma, 31 de marzo de 1768. Sobre este tema véase también A.G.S., Estado, leg. 6101, carta de Grimaldi a Tanucci de 29 de marzo. Una copia del Manifiesto, cuyo título era Memoria della Corte di Parma sulle lettere in forma di breve pubblicate ed affisse in Roma nel giorno primo febbraio 1768, en A.G.S., Estado, leg. 5254.

25. A.G.S., Estado, leg. 6101, carta de Tanucci a Carlos III, 12 de abril de 1768.

26. A.M.AA.EE, Santa Sede, Leg. 427, carta de Tomás Azpuru a Guillermo Du Tillot, Roma, 31 de marzo de 1768 .

27. El Nepote de Clemente XIII era Carlo Rezzonico, nacido en Venecia el día 23 de abril de 1724 y creado Cardenal por su tío en el Consistorio del 2 de diciembre de 1758, ocupando también los cargos de Secretario de Memoriales y Vicecancelliere sommista. Murió en 1799, 16 años después que su hermano, Giovanni Battista, a quien Clemente XIV había hecho cardenal en 1770.

28. A.M.AA.EE, Santa Sede Leg. 427, carta de Tomás Azpuru a Guillermo Du Tillot, Roma, 31 de marzo de 1768. El dictamen del Agente de Preces de España en Roma, Nicolás de Azara, sobre la negativa del Papa sigue al de Azpuru: «Las funciones de semana santa servirán de pretexto tal vez al Papa, para alargar la audiencia hasta después de Pascua. Miserable recurso! Pero que en manos de los pretes, suele producirles grandes bienes. Todo el ahinco de estos será, según mi dictamen, de ganar tiempo, y ver si pueden inclinar hacia la negociación; este es su fuerte»; carta de Azara a Roda, Roma, 31 de marzo de 1768, en El espíritu de D. Jose Nicolas de Azara, Madrid, 1846, tomo I, pág. 36-42.

29. A.M.AA.EE, Santa Sede Leg. 427, carta de Tomás Azpuru a Guillermo Du Tillot, Roma, 31 de marzo de 1768 . 
las reservas expresadas por el Cardenal, el Embajador francés había replicado que «la orden de su Corte era alternativa, y dejaba en arbitrio de recurrir a la segunda par$t e$, no pudiendo tener efecto la primera ${ }^{30}$. No cabe duda de que la respuesta de Clemente XIII había cogido por sorpresa a los ministros de la Casa de Borbón, obligándolos a cambiar los planes iniciales y recurrir a otros caminos. De hecho, aunque las «instrucciones» enviadas a los embajadores recogían todas las posibles réplicas de la Corte de Roma, como el caso de que se obligara Orsini y a los demás ministros a «uscir» del Estado Eclesiástico, no contemplaban la posibilidad de una negativa a la audiencia en común ${ }^{31}$. «No se havía previsto ni podido prever -escribía Du Tillot-que la audiencia no sería la obtenida, y (...) veo que ha tenido un éxito diverso contra nuestra expectación $»^{32}$.

En la carta ministerial al Cardenal Orsini, se destacaba, además, el hecho de que se daba la orden de manifestar «espressamente» al Papa la recusación de los cardenales filo-jesuitas Torrigiani, Negroni ${ }^{33}$, Boschi ${ }^{34}$, Buonaccorsi ${ }^{35}$, Castelli ${ }^{36}, \mathrm{y}$ «otro qualquier Cardenal ó Prelado» que consideraban unidos a la «Liga Jesuítica» y, en consecuencia, adversos a los Borbones ${ }^{37}$. Sin embargo, en opinión de Tanucci, sólo Torrigiani, Castelli y Boschi habían tomado directamente parte en la redacción del Monitorio, mientras que los demás «avevano o contradetto, o come pecore seguito» ${ }^{38}$. El Ministro no podía evitar señalar que las instrucciones eran «conseguenza di quel che é venuto dalla Corte di Spagna, pensato», reafirmando así su disconformidad con el planteamiento de la Corte de Madrid ${ }^{39}$. En cuanto a la actitud de Clemente XIII, es-

30. Ibídem.

31. A.G.S., Estado, leg. 6101, véase la carta ministerial al Cardenal Orsini, 22 de marzo de 1768.

32. A.M.AA.EE, Santa Sede Leg. 427, carta de Du Tillot a Azpuru, Parma, 10 de abril de 1768.

33. Pronotario Apostólico y Auditor de Clemente XIII, la exclusiva en contra de él duró sólo unas semanas. En junio de 1768, el Papa le asignó la difícil tarea de negociar con las cortes borbónicas, tras el rechazo de éstas a tratar con el Secretario de Estado, Torrigiani. Según Maria Claudia FERRARI, la designación de Negroni representó una «mezza vittoria» de las cortes borbónicas, ya que de esta manera se libraban de Torrigiani; vid. Maria Claudia FERRARI, «Il problema della soppressione della Compagnia di Gesù...», pág. 672. Sin embargo, según la opinión de Azara, el cambio adoptado por Clemente XIII era «obra pura y neta» del mismo Torrigiani, probablemente «por vengarse de Negroni», puesto que en Roma «todos» la tenían «armada contra él», una vez que los Borbones lo habían «absuelto de la exclusiva». Además, Azara informa que el Papa nombró a Negroni tras la «pedidura» de Aubeterre, que el Agente de Preces estimó «á lo menos intempestiva é inútil»; véase las cartas de Azara a Roda de 30 de junio de 1768 y la del 14 de julio de 1768, en El espíritu de..., tomo I, p. 84-85 y p. 92.

34. Nombrado arzobispo titular de Athenas en 1760, fue Maestre de Cámara y Consultor para los Sacros Ritos. Clemente XIII lo creó Cardenal el 21 de julio de 1766.

35. Secretario de la Sagrada Congregación de Obispos y Regulares, Clemente XIII le nombró Cardenal en 1761. Murió en 1776.

36. Creado Cardenal en 1758, fue designado por Clemente XIII miembro de la Congregación de Córcega en agosto de 1760, y Prefecto de la Congregación de Propaganda en el año 1763.

37. A.G.S., Estado, leg. 6101, véase la carta de Grimaldi a Tanucci de 5 de marzo de 1768.

38. A.G.S., Estado, leg. 6101, carta de Tanucci a Grimaldi, 7 de junio de 1768.

39. A.G.S., Estado, leg. 6101, carta ministerial al Cardenal Orsini, 22 de marzo de 1768. 
timaba que éste se había dejado probablemente influir también por la actuación del Embajador del Reino de Cerdeña, el Conde de Rivera ${ }^{40}$, que estaba en Roma para hacer «causa comune sfacciatamente con tutti li nemici della Spagna, della Francia, delle Sicilie» ${ }^{4 !}$.

Asimismo, en una carta al Rey Católico, el Ministro napolitano sospechaba que el Nuncio en París conocía el Plan antes de que éste fuera enviado Roma, ya que aquél pudo haber advertido a Torrigiani, por medio del mismo correo que llevaba la carta del Rey de Francia al propio Aubeterre ${ }^{42}$. Es por ello que, cuando Azpuru acudió a la audiencia concedida por el Santo Padre el 6 de abril, todas las reivindicaciones fueron rechazadas. A juicio de Du Tillot, el Embajador español chocó contra la «inflexibilidad» de un Papa «animado por los jesuitas», así como por aquellos Cardenales que habían tenido "parte en el consejo imprudente» dado a Clemente XIII ${ }^{43}$. Según cuenta el Agente de Preces español en Roma, Nicolás de Azara, el Papa

«no quiso leer, ni menos la memoria y manifiesto, y se protestó delante de un Santo Cristo que dará hasta la última gota de sangre, antes que revocar el breve de Parma: que aunque viejo y débil, y que lo queremos hacer pasar por un aturdido que no sabe de nada, todo cuanto se despacha, lo lee: y que dicho breve lo meditó y pensó muchos días antes; $y$ dijo á Azpuru que así lo podía decir á quien quisiera» ${ }^{44}$.

En las siguientes audiencias, a las que Azpuru y los demás ministros acudieron separadamente y hablaron «in nome dei tre Re dell'Augustissima Casa», el Pontífice

40. Giovan Battista Balbis, Conde de Rivera, Embajador de Cerdeña en Roma desde 1760 hasta 1777. En la correspondencia de Tanucci aparece una infinidad de veces su nombre, y las críticas a su actitud son reiteradas. Véase por ejemplo la carta de Tanucci a Grimaldi, de 7 de junio de 1768, en A.G.S., Estado, leg. 6101 .

41. A.G.S., Estado, leg. 6101, carta de Tanucci a Carlos III, 5 de abril de 1768. Interesante, sobre este tema, el parecer de Azara en una carta a Roda de 31 de marzo: «El conde de Rivera se ha declarado á banderas desplegadas, por los jesuitas, porque su córte se ha declarado también por ellos, siguiendo los pasos de los ingleses. Turín, así como Roma, no pueden oir nombrar la alianza de toda la casa de Borbon con la de Austria, porque con esta política pierden su sistema de enredar en medio de todos»; en El espiritu de ..., tomo I, pág. 37.

42. A.G.S., Estado, leg. 6101, carta de Tanucci a Carlos III, 12 de abril de 1768. Es notorio, a este propósito, el juicio negativo que Tanucci tenía sobre la capacidad de los franceses para tratar con Roma, y no escondía sus reservas al Rey de España y a Grimaldi. Véase por ejemplo las cartas a Grimaldi de 10 de mayo de 1768 y la del 16 de agosto del mismo año, así como la carta al Rey Católico de 15 de marzo de 1768, en la que el Ministro napolitano afirmaba: «Savissimo da tanti secoli é il Gabinetto di Francia, ma Vostra Maestá ha veduto per tante esperienze, che li Ministri che manda a Roma non conoscono Roma»; A.G.S., Estado, leg. 6101. Sobre la reacción de Tanucci tras la firma del Pacto de Familia de 15 de agosto de 1761, y más en general, sobre su desconfianza hacia los franceses, véase el ensayo de Sergio LOLLINI, «I problemi dell'adesione del Regno di Napoli al Patto di Famiglia del 1761. Dall'epistolario di Bernardo Tanucci», en Storia e Politica, 1983, 22(1), p. 72-113.

43. A.M.AA.EE, Santa Sede, Leg. 427, carta de Du Tillot a Azpuru, Parma, 16 de abril de 1768. Los demás ministros de la Casa de Borbón coincidían con la opinión del Secretario de Estado de Parma; así por ejemplo Azara argumentaba que los jesuitas «en toda la semana santa han empleado en calafatear al Papa». Carta de Azara a Roda, Roma, 7 de abril de 1768, en El espiritu..., Madrid, 1846, tomo I.

44. Ibidem. 
insistió en su negativa, tanto en retirar el Monitorio, como en hacer una «ricognizione pubblica» de la soberanía del Duque, «in riparo della offesa, e della usurpazione dei suoi diritti». La «pertinace negativa» del Papa no fue una sorpresa por Tanucci que, al contrario, veía en ella la habitual política de la Santa Sede, según la cual, había que llegar a una ruptura para luego poder hacer un ventajoso ajuste:

«Pensando ora alla pertinace negativa del Papa (...) ho creduto di ritrovarvi non quell'artifizio che i Romaneschi adulatori magnificano, e per cui trionfano a nostre spese, ma una politica solita di quella Corte, la quale tanto piú s'indurisce quanto piú vede il calore del nostro domandar la revocazione. Non anno (...) assicurata la coscienza, o temono dei popoli, non si contentano delle loro proibizioni, vogliono, e credono necessaria la nostra; di quá quell'orgoglio di Torrigiani, e quella pertinacia del Papa; di quá la speranza di rassettar tutto colla rottura anche del ritorno dei Gesuiti, li quali soffiono sul fuoco: É massima di quella Corte rompere per fare un buono e utile aggiustamento» ${ }^{45}$.

Mejor conocedor de la Corte romana, Tanucci veía en la actitud de Clemente XIII una estrategia ya adoptada en el pasado por sus predecesores ${ }^{46}, \mathrm{y}$ ante la cual, como única respuesta válida, aconsejaba el silencio y la intensificación de la política regalista:

«Il bastone alto, la bocca chiusa son li strumenti colli quali si deve mansuefare la tigre romana; cosí si può essere padroni in casa sua; cosí finirá di mettersi a guastar il bene pubblico delle nazioni e sarà il suo abbaiar ai sovrani quello, che fanno i cani alla luna» ${ }^{47}$.

Éste era el camino indicado por el Secretario de Estado de Nápoles para que los Borbones obtuvieran satisfacción por el «agravio» de Parma. Sin embargo, pese a las reiteradas advertencias, el Rey Católico no prestó atención a su fiel Ministro, pues estaba ya decidido a recurrir a represalias militares.

\section{LAS REPRESALIAS}

\section{Aviñon, Benevento y Pontecorvo}

El 1. de marzo de 1768, el Secretario de Estado de España, Jerónimo Grimaldi, envió una carta a Tanucci informándole del dictamen del Consejo Extraordinario so-

45. A.G.S., Estado, leg. 6101, carta de Tanucci a Carlos III, 19 de abril de 1768. Mientras viviera Clemente XIII, comentaba el Ministro, «non é sperabile l'aggiustamento», en A.G.S., Estado, leg. 6101, carta de Tanucci a Carlos III, 14 de junio de 1768. Sobre este tema véase también una carta de Tanucci a Grimaldi, en la que el Ministro insistía en denunciar el sistema adoptado por la Corte de Roma de «rompere per far un accordo vantaggioso»; A.G.S., Estado, leg. 6101, carta de Tanucci a Grimaldi, 10 de mayo de 1768.

46. El único Pontífice de los últimos nueve siglos que siempre rechazó el «aforismo romano = bisogna rompere per fare un buon aggiustamento», fue, a juicio de Tanucci, el «ottimo Lambertini», Clemente XII, «il quale professó che la Chiesa doveva pregar per la pace, e non poteva egli adattar la sua coscienza a quella massima, ch'ei ben sapeva essere stata dei suoi predecessori», en A.G.S., Estado, leg. 6101, carta de Tanucci a Carlos 111, 15 de marzo de 1768.

47. Carta de Tanucci a Galiani, 29 de abril de 1768, citada. en Rosa MINCUZZI, Bernardo Tanucci Ministro di Ferdinando di Borbone..., página 76. 
bre las represalias a adoptar «en caso que los Romanos se obstinen» en mantener el Monitorio contra la Corte de Roma ${ }^{48}$. A tenor de la decisión del Consejo, se mandaba que el Rey de Nápoles tomara las medidas oportunas para ocupar la ciudad de Benevento ${ }^{49}$, «al mismo tiempo» que las tropas francesas ocupasen Aviñón. Además, en la carta de Grimaldi, se señalaba que Carlos III se había conformado «enteramente» con dicho dictamen, y por eso esperaba que su hijo, el Rey de Nápoles Fernando IV, «en nada se apartara del Plan que su Augusto Padre ha adoptado» ${ }^{50}$. La decisión de ocupar las ciudades papales de Benevento, Pontecorvo ${ }^{51}$ y Aviñón para forzar a la Curia de Roma a anular al Monitorio, fue aceptada con muchas reservas por Tanucci, que intentó convencer al Rey de España y sus ministros de la «inutilitá» e «inefficacia» de la solución planteada, sin encontrar al final ningún respaldo a su sugerencia. Este tipo de represalia, a juicio del Ministro, no habría provocado ningún cambio en la política de la Curia romana. Muy al contrario, como él escribía, «sará compatita dalli popoli, che avranno veduta chiaramente l'invasione e fará la Chiesa figura compassionevole d'oppressa» ${ }^{52}$. Por lo tanto, este tipo de «rappresaglia» conllevaba el riesgo de presentar a la Corte romana frente la opinión pública como víctima y agraviada, y no como culpable. Y puesto que la sola ocupación no iba a persuadir al Papa de que cambiara su actitud, Tanucci estaba convencido de que al final serían las Cortes Católicas las que habrían de acudir a la mesa de negociaciones, haciéndole de este modo el juego a Roma:

«Non parlerá Roma, non revocherá, lascierá correre le possessioni sue in potere degli invasori, li quali finalmente, ferme stanti le cose di Parma, gli editti, gli exequatur, le giurisdizioni, e giá stabilite dalla giustizia, e dal tempo, e dall'uso, volendo per coscienza restituire, saranno i primi a parlare» ${ }^{53}$.

La publicación del Monitorio, «ingiuriosa e scandalosa insolenza commessa dalla corte di Roma contro quella di Parma», representaba, al contrario, una excelente ocasión para persuadir al Rey Católico de que había llegado el momento oportuno para llevar a cabo una necesaria y profunda reforma en el campo eclesiástico, y seguir, de este modo, la obra empezada en los primeros años de la Regencia e interrumpida

48. A.G.S., Estado, leg. 6101, Grimaldi a Tanucci, El Pardo, 1 de marzo de 1768.

49. Situada a unos $80 \mathrm{Km}$. al noroeste de Nápoles, Benevento es hoy en día una de las 5 provincias de la región Campania, junto a Avellino, Caserta, Salerno y Nápoles.

50. A.G.S., Estado, leg. 6101, Grimaldi a Tanucci, 1 de marzo de 1768. Hay que señalar en este punto, que conforme a las instrucciones de sus respectivos gobiernos, los tres embajadores en Roma debían comunicar al Pontífice que si sus peticiones no encontraran plena satisfacción, las tres Cortes se verían obligadas a respaldar «con tutti li mezzi», los derechos del Duque Fernando, sin especificar, desde luego, qué tipo de medidas se habrían adoptado; véanse la carta ministerial al Cardenal Orsini ya citada en A.G.S., Estado, leg. 6101.

51. En la represalia en contra de la Santa Sede, Francia y España decidieron de inmediato que las tropas napolitanas ocupasen también la pequeña ciudad papal de Pontecorvo, situada a medio camino entre Roma y Nápoles.

52. A.G.S., Estado, leg. 6101, carta de Tanucci a Carlos 111,17 de mayo de 1768.

53. Ibídem. 
en $1763^{54}$. En opinión de Tanucci, si los Borbones deseaban obtener satisfacción por el agravio de Parma, debían de atacar a Roma en sus intereses económicos, adoptando toda una serie de disposiciones «conformi alla vera disciplina della chiesa, e alla pratica dei primi dodici secoli $\gg{ }^{55}$. En lugar de las represalias militares, estimaba preciso, dentro del Reino de Nápoles, una ley de amortización, la reforma del Tribunal de la Nunciatura, la suspensión de las expediciones, la definición de las competencias del Nuncio, el nombramiento de todos los obispos del Reino, la abolición de las dispensas, y otras medidas dirigidas a rescindir la estrecha conexión entre la organización eclesiástica del Reino y la Curia romana, y limitar el dinero que llegaba a Roma ${ }^{56}$, puesto que, a los «curiali romaneschi» muy poco les interesaba «una cittá piú, o meno che abbia il Papa ${ }^{57}$ :

Preme il danaro dei benefizi, delle pensioni, degli appelli, delle dispense, della Dateria. Bisogna pensar al modo di toglier loro la maggior parte di questo, e ritornar Roma allo stato antico del Primato vero di S. Pietro" ${ }^{58}$.

El Ministro argumentaba su pensamiento explicando que estas disposiciones se podían adoptar en todos los dominios de los Borbones, es decir, que una intensificación de la política regalista se podía realizar, «con maggior danno di Roma», incluso en España y las Indias, mientras que la ocupación se haría solamente por parte de

54. El estancamiento de la política regalista en el Reino de Nápoles en 1763 coincidió con el cambio de la política de Carlos III ante la Santa Sede, culminado con la revocación en España del exequatur regium por decreto de 5 de julio, año y medio después de haberlo promulgado. La decisión del Monarca, que algo tuvo que ver en las dimisiones del Secretario de Estado español, Ricardo Wall, representó un duro golpe para la política anticurialista de Tanucci al perder el sostén imprescindible de su «señor y dueño». El cambio de Ricardo Wall por Gerónimo Grimaldi en la Secretaría de Estado, «no supuso -según Maximiliano Barrio- una marcha atrás en la política regalista, sino una redefinición del proyecto reformista». Vid Maximiliano, BARRIO GOZALO, «Política eclesiástica y religión a través de la correspondencia de Bernardo Tanucci y Jeronimo Grimaldi a mediados del setecientos», en Anthologica Annua, 1993, (40), pág. 224. A propósito del exequatur en España, véase del mismo autor también, «Carlos III y su actividad política a través de su correspondencia con Tanucci (1759-1783)» en Carlos III y la llustración, I, Madrid, 1988, pág. 296. Además, en abril de ese año murió Nicola Fraggianni (1686-1763), el más precioso y fiel colaborador de Tanucci. La muerte del Secretario de Asuntos Eclesiásticos, escribe Pia ONNIS, fue «un grave colpo per il partito anticurialista, e il Tanucci conveniva tristemente che i migliori ministri degli affari ecclesiastici erano finiti». Vid Pia ONNIS, «Bernardo Tanucci nel moto anticurialista del settecento...», Roma, 1971, página 359.

55. A.G.S., Estado, leg. 6101, carta de Tanucci a Grimaldi, 19 de abril de 1768.

56. Ibídem. Entre éstas, el Ministro hacía hincapié en el «valimento delle rendite ecclesiastiche intestate a quelli che stanno fuor dello stato», que consistía en despojar a quien residía fuera del Estado de Nápoles de los beneficios derivados de la posesión de bienes eclesiásticos, a fin de hacer, como explicaba a Carlos III, «un esatta e totale distribuzione al culto divino, e ai poveri», en A.G.S., Estado, leg. 6101, carta de Tanucci a Carlos III, 19 de abril de 1768. Sobre este tema, véase Maria Claudia FERRARI, «Il problema della soppressione della Compagnia di Gesù...», pág. 668.

57. A.G.S., Estado, leg. 6101, carta de Tanucci a Grimaldi, 3 de mayo de 1768. Véase tambíen la obra imprescindible de Franco Venturi, Settecento Riformatore. La Chiesa e la Repubblica dentro i loro limiti. 1758. 1774, Torino, Einaudi, 1976, páginas 232-233.

58. A.G.S., Estado, leg. 6101, carta de Tanucci a Grimaldi, 3 de mayo de 1768. 
Francia y Nápoles ${ }^{59}$. Además, señalaba la necesidad de restituir a los obispos la antigua jurisdicción que Roma les había usurpado a lo largo de los siglos, en particular sobre las órdenes regulares, y esto porque «li Vescovi son compagni, e fratelli del Primo Vescovo, non figli, ne schiavi» ${ }^{60}$. En su opinión, no había «cosa che faccia a Roma più paura dell'Ordine Episcopale» ${ }^{61}$. En la correspondencia del Ministro destaca claramente su pensamiento episcopalista, así como su hostilidad hacia las órdenes regulares y sus respectivos generales, considerados como una «milizia al servizio della politica mondana» de Roma:

«Io non so il male che abbia fatto in Spagna lo star li Generali degli Ordini Regolari in Roma e di la spargere clandestinamente nei subalterni superiori tutte quelle disposizioni, che insidiosamente ha voluto la politica mondana, e sempre pecuniaria, e giurisdizionale della Corte di Roma. Certamente in Italia il male é stato grandissimo. Basta per concepirne la mole, il considerare, che li Francescani Conventuali, li Carmelitani, li Dominicani, li Paolotti, li Gesuiti, li Teatini son entrati tutti come mendicanti incapaci di possedere, e tutti posseggono, e si sono arricchiti. Tutti devono essere sottoposti per Legge Divina ai Vescovi, poiché per legge Divina son posti i Vescovi regere Ecclesiam Dei; e gli Ordini regolari colla connivenza, e cospirazione di Roma si sono separati dai Vescovi $^{62}$.

Por este motivo, cuando en julio de 1768 Tanucci fue informado de que en España se había restablecido el exequatur, pese a expresar su satisfacción por considerar a dicho instituto como el «unico rimedio per conservar la regalia, la quiete dei sovrani, e delle nazioni, la disciplina cristiana $[y]$ la religione stessa cattolica», no pudo evitar indicar a Grimaldi, con una cierta desazón, que la pragmática no incluía las indulgencias, definidas como la «fiaccola che incendió la Germania e tutto il Settentrione colla eresia di Lutero», las dispensas matrimoniales, y sobre todo, las cartas privadas:

59. A.G.S., Estado, leg. 6101, carta de Tanucci a Carlos III, 17 de mayo de 1768.

60. A.G.S., Estado, leg. 6101, carta de Tanucci a Carlos III, 24 de mayo de 1768.

61. A.G.S., Estado, leg. 6101, carta de Tanucci a Carlos III, 9 de febrero de 1768. Sobre el episcopalismo de Tanucci, véase la obra de Francesco RENDA, L'espulsione dei Gesuiti dalle Due Sicilie, Sellerio, Palermo, 1993, páginas 19-26. Las ideas episcopalistas de Tanucci -escribe Maximiliano Barrio- así como de «otros políticos regalistas no son algo extraño, sino que reflejan el sentir general de los defensores del regalismo en el siglo XVIII, que propugnaban la jurisdicción episcopal jure divino, con merma de la jurisdicción del papado». Vid. Maximiliano BARRIO GOZALO, «Madrid y Roma en la segunda milad del siglo XVIII. La lucha contra las usurpaciones romanas», en Revista de Historia Moderna. Anales de la Universidad de Alicante, 1997, (16), pág. 78.

62. A.G.S., Estado, leg. 6101, carta de Tanucci a Grimaldi, 23 de agosto de 1768. "Questo riseder in Roma i Generali degli Ordini Regolari -protestaba Tanucci-é un grave male delle nazioni e della sovranitá, e una insidiosa al solito política di Roma (...). Per aver truppa in tutto il mondo cattolico, li Papi tolsero ai Vescovi con autoritá, che non avevano, poiché li Vescovi son compagni, e fratelli del Primo Vescovo, non figli, ne schiavi, tal giurisdizione; li regolari difesero l'esenzione colle sofistiche e scolastiche sottigliezze estesero la potestá Papale, la quale volle li Generali in Roma per far per mezzo loro nel mondo tutto quel, che alla loro politica conviene», en A.G.S., Estado, leg. 6101, carta de Tanucci a Carlos III, 24 de mayo de 1768. 
«Particolarmente li capi degli ordini religiosi anno soluto, e sogliono colle lettere private ai provinciali, agli abati, ai guardiani, ai priori, etc., scrivendo, alterar le regole, insinuare, impaurire, sedurre. Si é osservato in Italia, ove é antichissimo l'exequatur, che per li Gesuiti, cha an tanto fatto e tanto guastata l'antica disciplina, non vi é esempio che abbiano mai presentati brevi, bolle, rescritti della corte di Roma per l'exequatur; tutto ha fatto colle sue lettere, e colla cieca obbedienza dei suoi al Generale» ${ }^{63}$.

Por todos estos motivos, el Secretario de Estado y de la Real Cámara de Nápoles, Bernardo Tanucci, se oponía a las represalias militares, y pesa a que ya todo estaba decidido por las cortes de Madrid y París, no desistía en sus intentos de obtener la aprobación del Rey Católico como un «desiderio sincero e vivo del miglior servizio dell'Augustissima Casa» ${ }^{64}$. Informaba, por ejemplo, que en caso de ocupación, el nuncio de Nápoles ${ }^{65}$ tenía orden de volver a Roma, y que ésta, «agitata in tutto dallo spirito gesuitico», conseguiría así la ruptura, «poiché essendo certo che si ha da venire a composizione, spera e Roma e $i$ Gesuiti un accomodamento vantaggioso» ${ }^{66}$. En una carta de 17 de mayo a Carlos III, explicó con claridad sus razones y justificaba «la lunga e molesta diceria» por el hecho de haber visto al joven Rey de Nápoles, Fernando IV, palidecer al enterarse de la excomunión ya «risoluta, e distesa e pronta a stamparsi» en caso de ocupación:

«Di tal rappresaglia sará molto piú il rumore, che l'effetto sugli animi di quelli, che consultano mediatamente, o immediatamente il Papa, ai quali molto maggiore stimolo verrebbe dal diminuirsi quel danaro, che ha per benefici, pensioni, spogli, appelli, dispense, governo degli ordini regolari, che con fina politica ha Roma stabilito, il farsi da quella Capitale per mezzo dei rispettivi Generali per tutto il mondo cattolico dopo aver esimito tutti quegli Ordini regolari dalla giurisdizione dei vescovi, onde tutto si riduce a Roma, lá vada tutto il danaro. Vostra Maestá ben vede che questo sistema non é di Gesú Cristo, ne degli Apostoli, ne dei tempi apostolici, nei quali non erano ne frati, ne monaci, ne esenzione dei vescovi rispettivi, ma architettura di rapacitá romana, in danaro, giurisdizione e influenza sediziosa su tutti li Stati Cattolici» ${ }^{67}$.

63. A.G.S., Estado, leg. 6101, carta de Tanucci a Grimaldi, 14 de julio de 1768.

64. A.G.S., Estado, leg. 6101, carta de Tanucci a Carlos III, 31 de mayo de 1768.

65. El Nuncio en cuestión era Guido Calcagnini (1725-1807), que fue nombrado representante en Nápoles el 22 de febrero de 1765 y creado Cardenal el 20 de mayo de 1766. Fue el sucesor de Giuseppe Locatelli que desempeñó el cargo de nuncio apostólico hasta el 25 de septiembre de 1763. Desde esa fecha hasta el febrero de 1765 se produjo un vacío en la Nunciatura de Nápoles.

66. A.G.S., Estado, leg. 6101, carta de Tanucci a Carlos III, 31 de mayo de 1768. Véase a este respecto también las cartas de Tanucci a Carlos III de 26 de abril, y la carta de Tanucci a Grimaldi de 10 de mayo, en las que el Ministro daba por cierta la salida del Nuncio de Nápoles, e incluso la de París. Sin embargo, como el mismo Tanucci confirmará en sus cartas, tras la ocupación de las ciudades papales, el Nuncio de Nápoles no abandonó su sede. El Ministro napolitano justificó su errónea información imputándola a un engaño sufrido por Gaetano Centomani, el Uditore di Legazione de Nápoles en Roma, y a una conversación con el Conde de Kaunitz, hijo del Canciller austríaco y Embajador de Viena en Nápoles, el cual le había confirmado también esta noticia; A.G.S., Estado, leg. 6101, carta de Tanucci a Carlos III, 21 de junio de 1768.

67. A.G.S., Estado, leg. 6101, carta de Tanucci a Carlos III, 17 de mayo de 1768. 
Sin embargo, antes de que la carta saliera de Caserta ${ }^{68}$, Carlos III ya había decidido, de acuerdo con Luis XV, que las represalias se realizarían de forma simultánea el día 11 de junio, tras retrasarlas tres días para «no turbar la solemnidad» del Corpus Christi $^{69}$. En realidad, éste no fue el único retraso, puesto que, según la documentación consultada, la ocupación ya estaba planificada para primeros de mayo. Sin embargo, el matrimonio entre Fernando IV y la Archiduquesa de Austria, María Carolina, aconsejaron el aplazamiento para no poner al Rey de Nápoles en una situación embarazosa frente a la Corte de Viena ${ }^{70}$. Tanucci advertía sobre las graves repercusiones que podían derivarse de este hecho, y respondía a las presiones de los franceses que insistían en realizar la ocupación, señalando «il disturbo che verrebbe alla Sposa Regina, se coll'aria franca e trionfale che il Ministero Romano ha presa, ardisse passi forti, sentita che avesser l'invasione di Benevento, contro i Ministri della Corona» ${ }^{71}$.

68. A principios de la década de los sesenta, la Corte de Fernando IV se había trasladado al nuevo Palacio Real situado en la ciudad de Caserta, a unos $40 \mathrm{Km}$. de Nápoles. Las obras de construcción de la Reggia di Caserta, empezaron por iniciativa de Carlos III en 1752 bajo la dirección de Luigi Vanvitelli, y finalizaron en 1774 .

69. Con la «stimatissima confidenziale» de 10 de mayo, Grimaldi avisaba a Tanucci de la resolución tomada, confirmándole, de esta manera, que el «sistema» del Ministro napolitano «non ha meritata la sovrana approvazione», en A.G.S., Estado, leg. 6101. Véanse también las cartas de Grimaldi a Tanucci de 17 de mayo de 1768 y de Tanucci a Grimaldi de 31 de mayo de 1768. A este propósito, puede consultar también Manuel DANVILA, Historia General de España ..., página 264.

70. El matrimonio tuvo lugar por poderes el día 7 de abril en la ciudad de Viena, y el mismo día, la joven Reina emprendió el largo viaje que la condujo finalmente el 12 de mayo a las cercanías de Terracina, en los confines del Estado Pontificio, donde la esperaba el Rey de Nápoles, Fernando IV, recién instruido sobre la «opera matrimoniale». Dada la «totale ignoranza» de éste en los deberes conyugales, el Secretario de Estado había tenido que ponerle al día, empezando con la «spiegazione dei due sessi», tal como le había mandado el Rey Católico. Un nervioso y emocionado Tanucci informa que el mismo día de la llegada de María Carolina, los Reyes se dirigieron hacia el Palacio Real de Caserta, donde, al amanecer del día siguiente, y a pesar de algunas dificultades iniciales, fue consumado el matrimonio «perfettamente e tanto», hasta el punto de que el Ministro no excluía la posibilidad de que el Rey Católico pudiera tener un nieto dentro de nueve meses. De esta forma se acallaba el rumor de la impotencia del joven Rey de Nápoles, que tanta inquietud había provocado en el Secretario de Estado y en el Rey de España. Como la costumbre de la época exigía, y junto a otros dos funcionarios de su confianza, el Ministro había pasado toda la noche despierto en espera de obtener la feliz noticia por parte de su Rey. Al mismo tiempo, había retrasado la salida del despacho para España, previsto en un primer momento para la tarde del día anterior, porque tenía la esperanza de que la noche le trajera «la consolazione desiderata». En sus palabras se denota la felicidad por lo sucedido: «La cosa, Signore, é fatta. Spero, che Vostra Maestá mi perdonerá due parole del dettaglio, che ha messo in riposo la mia agitazione sull'importantissimo affare, sul quale non é mancato che aumentasse la mia inquietudine col seminar per le stanze una profezia d'impotenza. Il dettaglio é che per due volte per l'ostacolo nelle prime ore in vano, la terza sul far del giorno, perfettamente e tanto, che potrebbe la Maestá Vostra tra nove mesi aver un Nipote, che Dio ci conceda»; en A.G.S., Estado, leg. 6101, cartas de Tanucci a Carlos III, de 10 y 13 de mayo de 1768.

71. A.G.S., Estado, leg. 6101, carta de Tanucci a Carlos III, 17 de mayo de 1768. Incluso en Parma, como informa Du Tillot, se estima inminente la ocupación de Benevento para comienzos de mayo, «a menos de que el Rey de Nápoles quiera tal vez aguardar que su real esposa aia pasado y salido ia del Estado Eclesiástico», en A.M.AA.EE, Santa Sede, Leg. 427, carta de Du Tillot a Azara, Parma, 30 de abril de 1768 . 
El riesgo era demasiado alto, y un eventual retraso no habría representado, al cabo, ningún cambio significativo en la línea política de los Borbones:

«Non si puó pretendere che la Regina sposa, e Suocera passino sulle censure di Roma (...). Chi puó assicurare quel che penserebbe la Regina Sposa se ascoltasse scomunicato da Roma lo Sposo per l'invasione di Benevento? Quel che penserebbe il canonico tedesco confessore prima di consumarsi il matrimonio? (...). L'invasione una volta minacciata sembra necessaria; ma non sembra necessario l'esporsi colla celeritá e col differirla due settimane a pericoli gravi nella sostanza, e nel decoro» ${ }^{72}$.

En realidad, según nuestra interpretación, el Ministro intentaba retrasar al máximo la ocupación y esperar así un eventual cambio en la actitud del Rey de España, por el cual pasaba, como es notorio, cualquier decisión significativa para el Reino de Nápoles ${ }^{73}$. De modo especial, Tanucci se negaba a dar la conformidad a la represalia antes de que el ejercito francés invadiera Aviñón, dado que este proceder conllevaba el «pericolo» de que el joven Rey de Nápoles se metiera «primo e solo in un fuoco irretrattabile» ${ }^{74}$. A este propósito, nøs parece muy significativa el testimonio de Azara, que en una carta a Roda de 28 de abril de 1768 escribía:

«Pensábamos que esta semana se ocuparía infaliblemente Benevento; pero Tanucci nos ha escrito que ha suspendido esta ejecución hasta que sepa que los franceses han entrado en Avignon. Nos ha sorprendido esta salida porque las órdenes anteriores no parece que daban término á tanta tardanza» ${ }^{75}$.

Y una semana más tarde, Azara añadió que Tanucci «se está en sus trece de no querer ser el primero á hacer represalias, ni moverse, hasta que sepa que Francia haya empezado las suyas» ${ }^{76}$. Del análisis de las cartas del Agente de Preces al Secre-

72. A.G.S., Estado, leg. 6101, carta de Tanucci a Carlos III, 3 de mayo de 1768. El confesor de la Reina de Nápoles era el Canónigo de Praga, Antonio Gürther. Su designación en enero de 1768 alertó al Ministro que no escondió su disconformidad: «Si dice di dottrina sufficiente, fornito di maniere pulite, e pratico delle Corti. Questo carattere quadra mirabilmente con quel gesuitismo, della quale, si sa, che non aborrisce la Corte di Vienna», citado en AMBRASSI Domenico, «L'espulsione dei Gesuiti dal Regno di Napoli nelle lettere di Bernardo Tanucci a Re Carlo III», en Riformatori e ribelli a Napoli nella seconda metà del settecento, Nápoles, 1979, páginas 95-96. Sobre este tema véase también las cartas de Tanucci a Carlos III de 15 de marzo y de 26 de abril, así como la carta de Tanucci a Grimaldi de 12 de abril, en A.G.S., Estado, leg. 6101.

73. Aunque la minoría de Fernando IV hubiera terminado a principios de 1767, el Monarca mostraba poco interés en los asuntos políticos, y, en realidad, participaba sólo marginalmente en la actividad de gobierno. La posición de preeminencia de Tanucci en el seno del Gobierno de Nápoles, era debida principalmente al apoyo del Rey de España. Aunque discontinuo y tal vez contradictorio, este respaldo del Rey a la política reformista de Tanucci resultaría determinante para callar la facción conservadora, abanderada por el Príncipe de San Nicandro.

74. A.G.S., Estado, leg. 6101, carta de Tanucci a Grimaldi, 31 de mayo de 1768. Pero al mismo tiempo, Tanucci confesaba el temor de «dispiacere al Gran Padre ed Gran Fondadore» del Reino de Nápoles, al que, como él escribía: «amo, venero, e servo per tutte le cagioni quanto posso, e tanto, che preferisco la morte al pericolo di dispiacere alla Maestà sua», ibídem.

75. Carta de Azara a Roda de 28 de abril de 1768, en El espíritu de..., tomo I, pág. 53.

76. Carta de Azara a Roda de 5 de mayo de 1768, en El espíritu de..., tomo I, pág. 55. 
tario de Gracia y Justicia, destacan las críticas a la línea política adoptada por las cortes borbónicas en lo referente al tema de las represalias. La afinidad con Tanucci es evidente, incluso en el lenguaje incisivo que utiliza cuando se refiere a la manera de tratar con Roma. El 7 de abril, el día después de la primera audiencia de Azpuru, Azara redactaba:

«Según el plano se ocuparán Avignon y Benevento: y según mi juicio de nada servirá mas que dar motivo á los jesuitayos, de tratarnos de hereges, tiranos, janseinistas y diablos del infierno. A mucho lerdo, arriedo loco, decimos ahí. Mientras no lleguemos mas de cerca á la bolsa y á la persona, no hay que esperar que hagan bondad. Otro que Benevento seria si las Gobas Rezzónicas viesen sobre ellas un buen palo de fresno, y que les deshacía el peculio que con tantos afanes han juntado" "77.

"Siempre me confirmo -seguía el Agente de Preces-en que los primeros golpes de Avignon y Benevento los irritarán en vez de humillarlos, y que solo harán efecto los que será forzoso darles después, á la bolsa y á la personas. Si continuamos en pedir dispensas y en pagar pergaminos, se reirán de nuestras conquistas, como que saben que se las hemos de restituir al cabo ${ }^{78}$.

Una vez llegados a un acuerdo con la Curia romana, la restitución de las ciudades papales a la que se refería Azara representó otra de las grandes batallas perdidas por Bernardo Tanucci en su lucha personal contra Roma. Como hemos visto, el Ministro se había opuesto firmemente a las represalias militares, por estimarlas ineficaces para obtener la justa satisfacción tras el agravio cometido con el Monitorio. Sin embargo, esto no significaba que él no reconociera válidos los derechos del Rey de Nápoles sobre las dos ciudades. Al contrario, como escribió el 1 de marzo, antes de que fuera informado del dictamen del Consejo Extraordinario, la crisis provocada por la actitud de la Curia romana podía convertirse en una óptima ocasión para «mettersi in mano qualche cosa», como hacer valer, por ejemplo, «il diritto del Re sopra Benevento e Pontecorvo" ${ }^{79}$. Por lo tanto, una vez ocupadas las dos ciudades, la preocupación principal del Ministro se dirigió hacia la retención de éstas, y como él mismo explicaba al Rey Católico, había evitado a propósito emplear el término «rappresaglia» en los edictos de anexión para que los habitantes de las dos ciudades no pensaran que la ocupación iba a ser temporal. Por contra, le había parecido más apropiado resaltar explícitamente los derechos antiguos de la Corona de Nápoles ${ }^{80}$ :

«Pensai ancora che la parola rappresaglia avrebbe messo nei Beneventani l'opinione di che presto si farebbe la restituzione, e non contrarrebbero alcuna affezione al Governo del Re, ne concepirebbero quelle speranze che an poi mostrato d'aver concepito di essere liberati dal giogo dei preti» ${ }^{81}$.

77. Carta de Azara a Roda de 7 de abril de 1768, en El espíritu de.., tomo I, pág. 43.

78. Carta de Azara a Roda de 14 de abril de 1768, en El espíritu de..., tomo I, pág. 46.

79. A.G.S., Estado, leg. 6101, carta de Tanucci a Carlos III, 1 de marzo de 1768.

80. A.G.S., Estado, leg. 6101, carta de Tanucci a Carlos 1II, 14 de junio de 1768.

81. A.G.S., Estado, leg. 6101, carta de Tanucci a Grimaldi, 5 de julio de 1768. Según informaba el Ministro, los ciudadanos de Benevento y Pontecorvo habían mostrado su agrado por la anexión borbónica y la consiguiente salida del Gobernador Pontificio y de los demás ministros de Roma. Sobre este aspecto, véanse también las cartas de Tanucci a Grimaldi de 14 de junio de 1768 , y la de 26 de julio de 1768 . 
Igualmente, y con la misma finalidad, había ordenado a los comandantes de las tropas de ocupación que llevasen a cabo la expulsión de los jesuitas, de modo que nadie tuviera motivo para «sospettare che breve e temporario abbia ad essere il possesso del Re» ${ }^{82}$. Sin embargo, a pesar de las aseveraciones de Carlos III, según las cuales «en todo caso» el Rey de Nápoles «ha de retener á Benevento y Pontecorvo» ${ }^{83}$, los derechos de Fernando IV sobre las dos ciudades se hicieron incompatibles a lo largo de las negociaciones que condujeron a la extinción de la Compañía de Jesús en julio de 1773. De acuerdo con el nuevo Embajador en Roma, José Moñino, el mismo Grimaldi señalaba que Benevento, Pontecorvo y Aviñón se habían ocupado con las armas «por represalia por lo de Parma», y si no habían sido devueltas anteriormente, se debía exclusivamente a la necesidad de presionar a Clemente XIV por la cuestión jesuítica. Por eso, una vez extinguida la Compañía, cesaba «todo motivo y derecho de retención», y a Tanucci no le quedaba más que resignarse nuevamente ante las instrucciones procedentes de Madrid que sacrificaban otra vez más los intereses del Reino de Nápoles ${ }^{84}$.

\section{Castro y Ronciglione}

Tal vez, la única satisfacción que obtuvo el Secretario de Estado en la contienda con Roma en 1768, fue la de ver evitada la ocupación de los territorios de Castro ${ }^{85}$ y Ronciglione $^{86}$, pese a la insistencia de la Corte de Francia y las críticas que ésta reiteró a la actitud del Ministro. Dicha operación había sido planteada por las Cortes de Francia y España para «muovere il Papa a quella revocazione, reparazione, e soddisfazione, alla quale non pareva, che fosse disposto per l'occupazione di Avignone, e di Benevento ${ }^{87}$. Tras las represalias del 11 de junio, Francia y España se mostraron par-

83. Vid. por ejemplo la carta de Grimaldi a Tanucci de 27 de septiembre de 1768 en A.G.S., Estado, leg. 5039.

84. A.G.S., Estado, leg. 5039, carta de Grimaldi a Moñino, 22 de septiembre de 1772. Benevento y Pontecorvo se devolvieron definitivamente en 1774, tras poco menos de 6 años de Gobierno borbónico.

85. La antigua ciudad de Castro estaba situada en un promontorio al oeste del Lago de Bolsena, en los confines con la Toscana, a unos $100 \mathrm{Km}$. al norte de Roma. Ya sede obispal en el siglo VIII, fue elevada a ducado en 1538 a favor de Pier Luigi Farnese, sobrino del Papa Paulo III. Sin embargo, la presencia de este feudo dentro del territorio del Estado Pontificio fue mal tolerada por los sucesores de Alejandro Farnesio, dando lugar a un prolongado conflicto entre Roma y los Duques de Parma. La contienda llegó a su culminación en el año 1649, cuando, tras el asesinato del obispo de Castro, las tropas pontificias ocuparon definitivamente el Ducado arrasando la pequeña ciudad. Finalmente, la Corte romana compensó a los Farnese con una indemnización de un millón setecientos mil escudos por la pérdida de sus bienes.

86. Pequeña ciudad situada a unos $65 \mathrm{Km}$. al norte de Roma, y aproximadamente a $50 \mathrm{Km}$ al este del puerto de Civitavecchia. A mediados del siglo XVI, el antiguo condado de Ronciglione fue unido al Ducado de Castro bajo el gobierno de los Farnese.

87. A.G.S., Estado, leg. 6101, carta de Tanucci a Grimaldi, 19 de julio de 1768. Como informa Grimaldi, «la primera idea» sobre la represalia de Castro y Ronciglione fue del Consejo Extraordinario, aunque «Francia la tuvo y propuso casi al mismo tiempo». Sin embargo, serían más tarde los franceses quienes mostraran más insistencia en llevar a cabo la acción militar; en A.G.S., Estado, leg. 6101, carta de Grimaldi a Tanucci, 13 de septiembre de 1768. 
tidarias de una nueva acción militar contra Roma, proponiendo que Fernando IV hiciera valer los antiguos derechos de la Casa Farnese sobre los pequeños territorios que Roma, «con violenta iniquitá», le «spoglió» en $1649^{88}$. Sin embargo, en esta circunstancia, los Borbones no demostraron la «uniformitá» que había caracterizado su línea política en las dos ocasiones precedentes, dado que el Rey Católico no dio finalmente el respaldo necesario a la nueva represalia militar. A pesar de que la Corte de Francia, los embajadores Aubeterre, Azpuru, así como el Consejo Extraordinario de España, «y en fin, todos coinciden en el dictamen de que es preciso invadir á Castro e Ronciglione, si seriamente se desea traher los Romanos á la razón» ${ }^{89}$, Carlos III adoptó al final una resolución de puro compromiso, estimando

«acertadísima y muy propia para mantener y acrecentar el temor de los Romanos, ir moviendo y acercando algunas tropas acia los parages de ese Reyno, por donde se habrian de poner en marcha si con efecto se emprendiese la invasión" ${ }^{90}$.

Resulta muy atrevido explicar el por qué de la negativa del Rey Católico a la represalia de Castro y Ronciglione. En primer lugar, según nuestra opinión, cabe señalar que en vez de una verdadera oposición a la acción militar en contra de la Santa Sede, se trató más bien de una indecisión, fruto probablemente de sus notorios «escrúpulos» ${ }^{91}$. Sin embargo, detrás de su actitud había probablemente otros factores que en breve vamos a analizar. Por ejemplo, podría estar el temor de dejar a su joven hijo «solo in un fuoco irretrattabile», como le repetía a menudo Tanucci. De hecho, la ocupación de Castro e Ronciglione debía llevarse a cabo exclusivamente por el ejercito napolitano y, por lo tanto, toda la responsabilidad de la operación en contra de la Curia romana habría recaído sobre Fernanđo IV. Además de temer por la seguridad de su hijo, Carlos III quería con su actitud repetir quizá una operación dispuesta por Tanucci en febrero, tras la publicación del Monitorio de Parma. En aquella ocasión, según el Ministro, una declaración de excomunión preparada por Torrigiani «contro tutte le corti che avevan cacciati li gesuiti», fue suspendida sólo por el temor de una ocupación de Benevento, ya que un movimiento de tropas del ejercito napolitano en los alrededores de esa ciudad había hecho pensar a Roma que con dicha ocupación «si voleva punire l'attentato contro la Corte di Parma ${ }^{92}$. Por aquel entonces, Carlos

88. A.G.S., Estado, leg. 6101, carta de Tanucci a Grimaldi, 13 de septiembre de 1768. Según Danvila, que cita una nota del Duque de Choiseul al Conde de Fuentes, el Embajador de España en París, el Rey de Francia consideraba «más eficaz» la ocupación de Castro y Ronciglione que las represalias de Aviñón, Benevento y Pontecorvo; vid. Manuel DANVILA, Historia General de España..., p. 199-200.

89. A.G.S., Estado, leg. 6101, carta de Grimaldi a Tanucci, 26 de julio de 1768.

90. A.G.S., Estado, leg. 6101, carta de Grimaldi a Tanucci, 27 de septiembre de 1768.

91. Véase sobre este tema en especial, PINEDO IPARRAGUIRRE, Isidoro, «Los escrúpulos de Carlos III en su actuación política frente a la Santa Sede», en Letras de Deusto, 41 (1988). El término «indecisión» fue utilizado por Grimaldi en una carta a Tanucci, y en la respuesta de éste, se repite la palabra «indecisione» con referencia a la actitud del Rey sobre el asunto de Castro, en A.G.S., Estado, leg. 6101 , carta de Grimaldi a Tanucci, 26 de julio de 1768, y la respuesta de 16 de agosto de 1768.

92. A.G.S., Estado, leg. 6101, véase las cartas de Tanucci a Carlos III de 15 y 22 de marzo de 1768. 
III había aprobado la maniobra, y por eso Tanucci, seguro de contar con el respaldo del Rey Católico, y convencido de que la simple amenaza podía dar más frutos que la ocupación efectiva, ordenó más tarde otro movimiento de tropas hacia Pontecorvo:

«Ha il Re [Fernando IV] ascoltato con molta consolazione che Vostra Maestá abbia approvata la mossa della piccola truppa, che aveva verso Benevento disposto per trattenere le furie fanatiche di Torrigiani e dei suoi aderenti, ostinati a pubblicar la declaratoria contro tutte le Corti che avevan cacciati li Gesuiti e occupati li beni loro. In seguito degli ordini susseguenti di Vostra Maestá per l'insolente e precipitoso Formabrevis contro il Ministero di Parma, ha la Maestá sua ordinata la mossa di altra poca truppa verso Pontecorvo" ${ }^{93}$.

Es muy probable, en fin, que los esfuerzos de Tanucci por convencer al Rey Católico tuvieran éxito en esta circunstancia. El Ministro, como es fácil imaginar, se había opuesto firmemente al plan de ocupación, alegando motivos tanto políticos, como económicos y logísticos. En primer lugar, estimaba inevitable una expedición anfibia de «sei o sette mil uomini almeno», hasta los puertos de Orbetello y Monte Filippo, en la costa toscana, con la eventualidad de que «Roma potrebbe mandare subito qualche truppa da Civitavecchia», ${ }^{44}$ en cuyo caso, el ejército napolitano podía llegar a perder «dos o tres mil hombres por muerte ó diserción, en un país pútrido, abierto y habitado de gente enemiga de los Borbones» ${ }^{95}$. Además, la ocupación de Castro y Ronciglione habría representado una «grossa spesa», cuantificable en «doscientos mil pesos», es decir, un «dispendio gravissimo e poco sopportabile» por el Erario Real de Nápoles ${ }^{96}$. Por lo tanto, en lugar de cualquier otra represalia militar, que sólo «aumentaría la pertinacia romana nel negarsi alla revocazione del Formabrevis, alla soddisfazione e reparazione» ${ }^{97}$, Tanucci mantiene la postura de «aspettare che Roma venga apertamente proponendo negoziazione», y entre tanto seguir con aquel firme silencio que no se había adoptado anteriormente ${ }^{98}$. En cuanto a los territorios de Castro e Ronciglione, escribía que Nápoles estaba dispuesto a dejarlos definitivamente al Estado Pontificio a cambio del poder de designación de los más de cien obispos del Reino que quedaban en manos del Papa, y del establecimiento del Tribunal de la Nunciatura:

"Il Re colla franchezza propria del suo Rango é pronto a rilasciar Castro e Ronciglione in perpetuo al Papa, e a prendersi in qualche compenso le nomine che gli manca-

93. A.G.S., Estado, leg. 6101, carta de Tanucci a Carlos III, 12 de abril de 1768.

94. A.G.S., Estado, leg. 6101, carta de Tanucci a Grimaldi, 7 de junio de 1768.

95. A.G.S., Estado, leg. 6101 , carta de Grimaldi a Tanucci, 20 de septiembre de 1768 . «In quelle pessime arie -advertía el Ministro- nell'estate e nell'autunno molta gente potrá perire, molta sará la diserzione; molte le difficoltá nel paese nemico, ed aperto e vasto»; A.G.S., Estado, leg. 6101, carta de Tanucci a Grimaldi, 19 de julio de 1768 .

96. A.G.S., Estado, leg. 6101, carta de Tanucci a Grimaldi, 19 de julio de 1768, y también la de Grimaldi a Tanucci de 20 de septiembre de 1768.

97. A.G.S., Estado, leg. 6101 , carta de Tanucci a Grimaldi, 28 de junio de 1768.

98. A.G.S., Estado, leg. 6101, carta de Tanucci a Grimaldi, 18 de octubre de 1768. 
no dei Vescovi di questo Regno; ed oltre a questo la facoltá di Legato a Latere pel Nunzio quanto agli appelli, acció che possa giudicar la terza istanza delle cause ecclesiastiche con tre Auditori Regnicoli perpetui» ${ }^{49}$.

El «trueque de los derechos» sobre los dos territorios no parecía al Ministro una pretensión excesiva, puesto que, como él mismo señalaba, el Rey de Cerdeña había obtenido a lo largo de aquel siglo el derecho de nombramiento de todos los obispos de su Reino, «senza cedere nulla della sua sovranitá», y en Toscana, durante el pontificado del «fortissimo» Pío V, se había creado un Tribunal de la Nunciatura «senza ceder cosa alcuna» ${ }^{100}$. Además, en lugar de la ocupación de Castro y Ronciglione, resultaba mucho más ventajoso que los Borbones ostentaran dichos derechos en el momento del acuerdo con Roma, a fin de negociar también la conservación de las ciudades de Benevento y Pontecorvo. Tanucci estaba convencido de que Roma habría aceptado la permuta, «per quel grande eccesso di rendita di Castro su quella di Benevento». De hecho, la primera proporcionaba a Roma «centomila scudi romani», mientras que Benevento y Pontecorvo aseguraban «appena» cuatro mil ${ }^{10 i}$ :

«Quando il Papa avrá revocato il Formabrevis, e fatta l'estinzione dei Gesuiti, e tutto quello che gli sará domandato, tornerá alle nostre prime proposizioni di esser Benevento y Avignone rappresaglie, che fattosi dal Papa quello che si domando, si devono restituire. Allora sarebbe per noi il tempo di dire, che siccome il Papa non ha voluto restituir mai Castro e Ronciglione perché troppo vicini a Roma, cosí essendo Benevento troppo vicino a Napoli, vuole il Re negoziare Benevento con Castro e Ronciglio$n e{ }^{102}$.

El asunto de Castro dio lugar también a un incidente diplomático entre Francia y Nápoles causando la «estrañeza y sentimiento» del Rey de España. Según noticias enviadas por Azpuru a la Corte de Madrid, los representantes diplomáticos de Nápoles en Roma, Orsini y Centomani, habían «hecho público» que la Corte de Nápoles había «determinado no hacer invasión alguna en Castro y Ronciglione». En virtud de las «seguridades» dadas por los dos ministros napolitanos, escribe Grimaldi,

99. A.G.S., Estado, leg. 6101, carta de Tanucci a Grimaldi, 30 de agosto de 1768. Según informa el mismo Tanucci, el Rey de Nápoles nombraba solamente una quinta parte de los obispos del Reino, en A.G.S., Estado, leg. 6101, carta de Tanucci a Grimaldi, 16 de agosto de 1768.

100. A.G.S., Estado, leg. 6101, carta de Tanucci a Grimaldi, 11 de octubre de 1768. La idea de permutar los derechos sobre Castro y Ronciglione por la designación real de los obispos del Reino no fue abandonada por el Ministro. En julio de 1776, a unos meses de su destitución, se propuso tratar directamente con Roma, enviando a Pío VI unas cartas en las que planteaba al nuevo Pontíftce la «commutazione» de dichos derechos. Parece que el nuevo Pontífice se mostraba inclinado a consentir la petición, y el 1 de octubre el Ministro informaba a Carlos III de la «promessa» del Papa «di dar li vescovadi papalini ai raccomandanti dal Re». Sin embargo, como escribe Rosa MINCUZZI, el despido de Tanucei por obra de la Reina Maria Carolina, le impidió llevar a cabo su último servicio al Reino de Nápoles, en Rosa MINCUZZI, Bernardo Tanucci Ministro di Ferdinando..., página 89.

101. A.G.S., Estado, leg. 6101 , carta de Tanucci a Grimaldi, 16 de agosto de 1768.

102. A.G.S., Estado, leg. 6101, carta de Tanucci a Grimaldi, 13 de septiembre de 1768. 
«han salido los Romanos del general abatimiento en que los tenía el temor, y asi Torriggiani y sus partidarios, como los Jesuitas, han vuelto a lebantar la cabeza, y a manifestar nuevo espiritu y corage» ${ }^{103}$.

La réplica del Secretario de Estado de Nápoles fue muy dura. En su opinión, la noticia no era más que una «calunnia» de Aubeterre, a cuya «fonte beve Azpuru», dado que él no había «mai parlato, ne scritto» sobre Castro a los embajadores en Roma, y que en todo el asunto de Castro y Ronciglione, Nápoles no había «fatto altro che obbedire, come doveva» ${ }^{104}$. Al contrario, argumentaba Tanucci, el Nuncio en París escribía que la Corte de Francia era la que estaba «placata e conciliata», mientras que España y Nápoles se mantenían «en su ardor», y que los mismos rumores iban «esparciendo en Roma los franceses residentes allí». Aunque decía no creer en estas noticias, siendo «una suposición no sólo contraria á la verdad, sino á las ardentísimas instancias que esta haciendo el Embajador Aubeterre», añadía luego que «alguna intención ocultà se podía entrever detrás de todo eso ${ }^{105}$. La polémica entorno a la actitud del Ministro y sus colaboradores en lo referente a Castro, llegó a su culminación al final de agosto, cuando el Embajador Orsini, tal vez como «disculpa» por su anterior actuación, confiaba al Cardenal Cavalchini que ya «estaba resuelta la invasión de Castro y Ronciglione» para comienzos de octubre, y, hecho más grave, explicaba que la Corte de Nápoles «había tomado esta resolución, no por voluntad propia, sino movido de la instancias de la Corte de París» ${ }^{106}$. Las «confianzas inoportunas» del Embajador de Nápoles, según se comentaba con preocupación en Madrid, habían dado a entender a Roma que entre las cortes borbónicas «había diferencia de opinio-

103. A.G.S., Estado, leg. 6101, carta de Grimaldi a Tanucci de 26 de julio de 1768.

104. A.G.S., Estado, leg. 6101 , carta de Tanucci a Grimaldi, 16 de agosto de 1768 . Sobre este punto véase Manuel DANVILA, Historia General de España... p. 205, en la que el autor incurre en un pequeño error que nos permitimos señalar. Danvila habla de un «enojo» de Tanucci contra Azpuru, y escribe: «en cuya fuente (...) bebía D'Aubeterre». Sin embargo, un atenta lectura del complicado italiano de Tanucci, demuestra claramente que el Ministro se refería al Embajador francés, «al cui fonte beve Azpuru». Es decir que este último envió las noticias a la Corte de Madrid dando la versión de Aubeterre, el verdadero autor, según Tanucci, de la «calunniosa malignitá» sobre Orsini y Centomani.

105. Sobre este complicado asunto, véanse las cartas de Tanucci a Grimaldi de 5 de julio, 16 de agosto y la de 27 de septiembre de 1768, así como la de Grimaldi a Tanucci de 26 de julio, A.G.S., Estado, leg. 6101. Interesante es el testimonio que da Azara sobre el estado de ánimo de Aubeterre, al enterarse éste de la negativa a ocupar Castro: «El Embajador de Francia está colérico de una manera, por esta suspension, que es gusto oirlo: ayer me mostraba las órdenes que días atrás le daba Choiseul para declarar al Papa expresamente, que iba á ocupársele Castro»; carta de Azara a Roda, Roma, 28 de jullio de 1768, en El espíritu de..., Madrid, 1846, tomo I, pág. 97.

106. A.G.S., Estado, leg. 6101, carta de Grimaldi a Tanucci, 13 de septiembre de 1768 . Desde Nápoles, Tanucci defendía a Orsini, replicando que el Embajador no había hecho, en la conversación con Cavalchini del 18 de agosto, «alcuna menzione della Francia». Con su peculiar ironía, Tanucci explicaba que tal vez el «equivoco» había nacido «per qualche difetto d'orecchie» de Clemente XIII en la audiencia al Cardenal Cavalchini de 19 de agosto, y que con su notorio «spirito torbido e maligno», Torrigiani había luego aprovechado la ocasión para desprestigiar, tanto a Orsini como a él mismo, ante la Corte de España; A.G.S., Estado, leg. 6101, carta de Tanucci a Grimaldi, 4 de octubre de 1768. 
nes y fines», y que alguna de ellas procedía «contra su dictamen y forzada de las demás» ${ }^{107}$. Además de manifestar la falta de uniformidad de las Cortes de Familia, el incidente dio lugar a una seria crítica a la actitud de Tanucci por parte de los franceses, acusándole de resistirse en realidad a las órdenes de ocupación, y demostrar poco interés por el desagravio de la Corte de Parma. En una carta a Grimaldi de 11 de octubre, Tanucci recordaba con cierta amargura el tenor de las acusaciones francesas:

«l'Ambasciatore colli suoi francesi biasimavano questa Corte, e me particolarmente perché non si eseguiva la convenuta, tra li due Capi della Casa, occupazione di Castro. Il biasimo ogni giorno aumentava. La vivezza francese arrivó ad accusarmi di discordare, e di aver poca cura del decoro della Corte di Parmas ${ }^{108}$.

\section{A MODO DE CONCLUSIÓN: LA CUESTIÓN JESUÍTICA}

Finalmente, Castro y Ronciglione no se ocuparon. La indecisión del Rey de España bloqueó una operación que parecía inminente a mitad de verano e incluso hasta final de octubre. Es muy probable que la oposición de Tanucci fuera determinante a este propósito, pero sólo en el sentido de que pudo influir en la actitud del Rey Católico. Y es que, si éste hubiera adoptado las resoluciones del Consejo Extraordinario y de la Corte de Francia, nada hubieran podido las razones del Reino de Nápoles, tal como ocurrió con las represalias del 11 de junio. La posición subordinada de la Corte de Nápoles impedía al Ministro tomar parte en este tipo de decisiones. Como es notorio, toda la actividad de su Gobierno estaba condicionada por la estrecha dependencia a la política española ${ }^{109}$.

Sin embargo, la satisfacción de ver evitada la realización de una operación a la que era totalmente contrario duró muy poco tiempo, porque otra «amarezza» le habría de traer el correo con noticias proveniente de España. El 13 de diciembre, llegaba a Nápoles una carta de Grimaldi que le informaba sobre la decisión del Rey Católico de pedir al Pontífice, «absoluta y positivamente», la extinción de la Compañía de Jesús, «como artículo separado de los negocios de Parma»"1". La noticia representó un duro golpe para el Ministro, que sólo una semana antes, en respuesta a un «comando» de Carlos III, había explicado claramente las razones por las que se oponía al planteamiento "'. A la orden del Rey de España de exponer «francamente» su punto

107. A.G.S., Estado, leg. 6101, carta de Grimaldi a Tanucci, 13 de septiembre de 1768. Azara confirma la inoportuna confidencia de Orsini al Cardenal Cavalchini, pero disculpa a Tanucci.

108. A.G.S., Estado, leg. 6101, carta de Tanucci a Grimaldi, 11 de octubre de 1768.

109. Este tema está analizado con lucidez por Enrica DELLE DONNE, Chiesa e potere nel Mezzogiorno. Istituzioni ed economia. 1741-1815, Edisud, Salerno, 1990, páginas 5-26.

110. La carta en cuestión en A.G.S., Estado, leg. 6101, Grimaldi a Tanucci, 29 de noviembre de 1768.

111. Véase la carta de Grimaldi de 22 de noviembre, en la que le comunicaba que el Rey quería que expusiera su parecer sobre la «conducta y procedimientos ulteriores con la Corte de Roma», en A.G.S., Estado, leg. 6101. Sobre este espinoso asunto remitimos también a la obra ya citada de Maria Claudia FERRARI, «Il problema della soppressione della Compagnia di Gesù ...», pág. 673. 
de vista, Tanucci había contestado mostrando todo su escepticismo sobre la posibilidad de que un Papa «italiano, non amico dei Borboni, governato dal Generale dei Gesuiti, $[e]$ che dopo le loro espulsioni ha fatto Bolle in lode dei Gesuiti», pudiera consentir la extinción de la Compañía ${ }^{12}$. El 22 de noviembre, antes de recibir las noticias de Madrid, Tanucci explicaba a Grimaldi que, en su opinión, era «piú facile aver Avignone e Benevento, e la nomina dei Vescovi, e il Tribunal della Nunziatura, che l'estinzione della Compañía, e la revocazione del Formabrevis» ${ }^{113}$. Por eso, si Clemente XIII hubiera admitido la remota posibilidad de «metter l'abolizione dei gesuiti in trattato», lo habría hecho sólo a través de un «processo», con todas las consecuencias que dicha solución conllevaba ${ }^{114}$. Además de ser una «indecenza» para los Borbones, al «star fuor dei loro stati, e in Roma, in figura di accusatori e litiganti colli gesuiti», Tanucci señalaba el peligro de que el proceso se prolongara considerablemente según los deseos de la Corte romana, dando la posibilidad a los jesuitas de proceder «colle solite arti mondane» para «imbrogliarlo» ${ }^{115}$. En estas condiciones, por lo tanto, había que considerar la posibilidad de que el proceso pudiera terminar con una

112. A.G.S., Estado, leg. 6102, carta de Tanucci a Grimaldi, 13 de diciembre de 1768. Tanucci hace referencia en este punto a la Bula Apostolicum Pascendi de 7 de enero de 1765 , en virtud de la cual el Pontífice calificaba de «óptimo» el Estatuto de la orden pese a las expulsiones de Francia y Portugal.

113. A.G.S., Estado, leg. 6101, carta de Tanucci a Grimaldi, 22 de noviembre de 1768.

114. A.G.S., Estado, leg. 6102, carta de Tanucci a Grimaldi, 13 de diciembre de 1768 . El planteamiento de Bernardo Tanucci sobre este asunto era bien conocido en Madrid. El Ministro había ya expresado a Carlos III su contrariedad al plan del Duque de Choiseul de mediados del año anterior, sobre la oportunidad de pedir al Papa la extinción de la Compañía de Jesús, vid. José A. FERRER BENIMELLI, «Carlos III y la extinción de los jesuitas», en Actas del Congreso Internacional sobre "Carlos III y la Ilustración", Madrid, Vol. I, páginas 245-250. El proyecto de Choiseul no encontró tampoco el apoyo esperado de la Corte de Madrid. Ante la propuesta francesa, Carlos III mantuvo una «actitud expectante» y mostró mayor interés en otra iniciativa paralela de la Corte de Lisboa, que finalmente «fue la que emprendió en Madrid los pasos conducentes a obtener de Roma la extinción» de la Compañía; Enrique GIMÉNEZ LÓPEZ, «Portugal y España en la extinción de la Compañía de Jesús», en Actas del Congreso Internacional sobre «Los Jesuitas españoles expulsos: su contribución al saber sobre el mundo hispánico en la Europa del Siglo XVIII», Berlín, abril 1999. El ingreso de Portugal en las negociaciones con la Santa Sede no fue recibido por Tanucci con mucho entusiasmo. Muy al contrario, la incorporación de una potencia que no tenía relaciones diplomáticas con Roma desde 1760 , habría provocado «piú resistenza che impeto», y además, su último embajador, Almada, era «in Roma screditado, e odiosissimo». Por lo tanto, escribía el Ministro, «se entra il Portogallo, l'aggiustamento sará lungo, difficile, intrigato»; en A.G.S., Estado, leg. 6101, carta de Tanucci a Grimaldi, 16 de agosto de 1768 .

115. A.G.S., Estado, leg. 6102, carta de Tanucci a Grimaldi, 13 de diciembre de 1768. La expresión citada: «colle solite arti mondane», con referencia al arte jesuita de tratar los asuntos mundanos, la emplea Tanucci en la «Memoria» de la Corte de Nápoles, que junto a las de Francia y España, fueron entregadas al Papa a fin de solicitar formalmente la extinción de la Compañía. Sin embargo, la muerte imprevista de Clemente XIII el 2 de febrero de 1768, impidió que una Congregación de los Cardenales, a este fin reunida, pudiera dictaminar sobre ella. El Cónclave, como es notorio, resolvió indirectamente la cuestión. Una copia de la Memoria que el Embajador Orsini entregó el día 24 de enero de 1769, ocho días después de la española y cuatro de la francesa, puede consultarse en A.G.S., Estado, leg. 6102, carta de Tanucci a Grimaldi, 27 de diciembre de 1768 . 
sentencia desfavorable, con lo cual, las repercusiones políticas para los Borbones habrían sido incalculables. «Quali conseguenze -explicaba el Ministro- se non si compie un processo convincente, e non viene favorevole la sentenza? $\gg^{116}$.

Pero, ¿qué razones habían llevado a Tanucci -cuya «jesuitofobia» era notoria en todas las cortes- a mantener una actitud negativa ante la decisión de la Corte de España? ${ }^{177}$. El móvil principal, a nuestro criterio ${ }^{118}$, reside en el precio que los Borbones habrían tenido que pagar para que el Papa aceptara su petición, porque estaba claro que sólo a cambio de significativas concesiones, Clemente XIII hubiera podido extinguir la Compañía:

«Se si tratterá infinite amarezze, lunghe contestazioni, mille sutterfugi s'incontreranno; indubitabile sará il pericolo o di rottura o di perdere tutto il fatto, o una gran parte dello stesso, e con esse il decoro e il bene tutto, che colle dottrine ben fondate si potrebbe conseguire per le nazioni e per lo Stato ${ }^{\$ 19}$.

El Secretario de Estado temía que la capacidad de tratar de los Romanos habría llevado a Francia y España y, en consecuencia a Nápoles, a sacrificar aquel programa de reformas económicas que estimaba no menos importante que la definitiva desaparición de los jesuitas. Por lo tanto, no cabe duda de que Tanucci deseaba el fin de la Compañía; sin embargo, tras la expulsión de ésta «dai due terzi delle Nazioni Cattoliche», esto es de Portugal, Francia, Nápoles, Parma, y por último de Malta ${ }^{120}$, opinaba

116. A.G.S., Estado, leg. 6102, carta de Tanucci a Grimaldi, 13 de diciembre de 1768.

117. La lucha contra la Compañía de Jesús fue, como es notorio, uno de los objetivos más anhelados por Bernardo Tanucci. La numerosa bibliografía tanucciana ha analizado muy ampliamente este aspecto, haciendo hincapié, en modo especial, en la expulsión de los jesuitas del Reino de Nápoles en noviembre de 1767. Dicha expulsión fue decretada por la Giunta degli Abusi, el Consejo Extraordinario creado por Tanucci con la finalidad de superar la oposición de los numerosos consejeros de Gobierno tilo-jesuitas. En lo referente al estudio de la expulsión de Nápoles y a la acción política de su promotor, hay que añadir a los trabajos ya citados, las siguientes aportaciones: Enzo D’ALESSANDRO, «L'abolizione della Compagnia di Gesù e l'espulsione della Sicilia nel 1767», Archivio Storico Siciliano, 9, 1959; Pia ONNIS, «L'abolizione della Compagnia di Gesù nel Regno di Napoli» en Filippo Buonarroti e altri studi, Roma, 1971; Egidio PAPA, «I beni dei gesuiti e i preliminari della loro espulsione dal Regno di Napoli nel 1767», Rivista di Storia della Chiesa in Italia, 30, 1976; Enrica ROBERTAZZI DELLE DONNE, L'espulsione dei gesuiti dal Regno di Napoli, Librería Scientifica, Napoli, 1970.

118. De opinión totalmente contraria, a este respecto, es el jesuita Domenico AMBRASSI en su estudio «L'espulsione dei Gesuiti dal Regno ...», página 97.

119. A.G.S., Estado, leg. 6101, carta de Tanucci a Grimaldi, 29 de noviembre de 1768.

120. El 22 de abril de 1768 la Compañía de Jesús sufrió otro golpe al ser expulsada de la isla de Malta, feudo del Reino de Nápoles. Dicha expulsión fue adoptada tras la fuertes presiones del Gobierno de Nápoles y pese a las «tremendas cartas de amenazas» que Torrigiani enviaba a la máxima autoridad de la isla, el Gran Maestre de la Orden de Malta; A.G.S., Estado, leg. 6101, carta de Grimaldi a Tanucci, 8 de marzo de 1768. Y como agradecimiento por la «condescenza al'insinuata espulsione dei Gesuiti», Tanucci da noticia de que, en base a una orden de Carlos III, el Gobierno de Nápoles vendió incluso a Malta «qualche tratta di grani siciliani» a un precio especial; A.G.S., Estado, leg. 6101, carta de Tanucci a Carlos III, 24 de mayo de 1768. El Gran Maestre de Malta hizo público el hecho de que los jesuitas fueron expulsabados sin más mótivo que una sola orden de Nápoles, provocando 
que otras naciones hubieran seguido el ejemplo, y la Compañía hubiera de esta forma desaparecido «naturalmente», sin la necesidad de tratar sobre su extinción y sacrificar los propios intereses, entre ellos, la restitución de los territorios ocupados el 11 de junio $^{121}$. El planteamiento del Ministro se resume con sus palabras:

«Torno dunque al mio sistema del silenzio. Colla minaccia sola di Castro si terrá Roma in freno per quel molto che resta a fare nel sistema dei Regolari e degli appelli per tutte tre le nazioni, e per la Dateria rispetto alle Sicilie, e per li Spogli e altri emissari di tanto danaro, anche s'impoverisce la Nazione per ingrassar lo stato del Papa, e si spopola anche il paese per tanti, che a spese del Regno, passano a Roma» ${ }^{122}$.

Llevando a cabo estas reformas, añadía Tanucci, los Borbones obtendrían una fama «memorabile» por dispensar «tanto bene ai loro popoli», mientras que la pérdida sufrida por Roma sería la «giusta pena» por las reiteradas defensas a la orden jesuita ${ }^{123}$.

Pero sus palabras quedaron en letra muerta. Por segunda vez en menos de un año, no sólo no habían tenido en cuenta su punto de vista, sino que tampoco habían esperado que su dictamen llegase a destino. En una carta a Nicolás de Azara, el Ministro de Nápoles reconstruía los hechos confesando su amargura:

«Il silenzio che io predicava per Parma arrivó alla corte a cosa risoluta. Sará anche in tal punto arrivata quest'ultima seconda predica. Nel primo caso parlai spontaneo, nel secondo mi é stato ordinato il mio parere, e si é risolto prima che potesse arrivare la mia risposta.

\section{Prego Dio che conservi il decoro e la quiete» ${ }^{124}$.}

las críticas y protestas de Tanucci. Así proclamaba el edicto de expulsión de 22 de abril: «Compiaciutosi Sua Maestá il Re delle Due Sicilie farci consapevoli d'aver espulsi da suoi Regni per delitti gravissimi di Stato tutti li Religiosi della Compagnia detta di Gesù, con ricercarci a tenor dei Patti sopraccennati la di loro espulsione da queste nostrte Isole, siamo venuti, secondo le dette massime sinora sempre praticate, alla determinazione di comandare, siccome colle presenti, comandiamo l'espulsione da questo nostro Dominio di tutti gli individui di questa Società, proibendo loro, ed agli altri che professeranno lo stesso instituto il ritorno per tutti i tempi avvenire». Una copia del edicto en A.G.S., Estado, leg. 6101. Sobre la reacción del Ministro véanse por ejemplo las cartas de Tanucci a Grimaldi de 4 y 10 de octubre de 1768, A.G.S., Estado, leg. 6101. Sobre la expulsión de Malta puede consultarse también Francesco RENDA, L'espulsione dei Gesuiti... páginas 70-71.

121. Ya en agosto de 1768, ante la oportunidad de incluir a Portugal en las negociaciones con Roma para pedir la extinción de la Compañía, Tanucci escribía : «Forse a vista di questa impossibilitá non sarebbe male restar come stiamo; gli editti di Parma si osservano, il Formabrevis é abolito da cinque Prammatiche e da tre cuarti del mondo cattolico. Avignone e Benevento perđuti saranno alla posteritá due monumenti della punita temeritá di Roma (...). Insistere sull'aggiustamento será un confessare che quel che si é fatto aveva bisogno dell'approvazione del Papa. E verrá anche un nuovo legame alle mani dei Sovrani per le provvidenze economiche, necessarie sempre piú alli Stati», en A.G.S., Estado, leg. 6101, carta de Tanucci a Grimaldi, 16 de agosto de 1768. Sobre este tema remitimos también a Maria Claudia FERRARI, «Il problema della soppressione della Compagnia di Gesù ...».

122. A.G.S., Estado, leg. 6102, carta de Tanucci a Grimaldi, 13 de diciembre de 1768.

123. Ibídem.

124. Carta de Tanucci a Azara de 17 de enero de 1769, citada en Maria Claudia FERRARI, «Il problema della soppressione della Compagnia di Gesù ...», pág. 673-674. 